\title{
A Study of Explicit and Implicit Means of Connection in Monologic Supraphrasal Reported Speech
}

\author{
Yelena Mkhitaryan, Nare Tamoyan \\ Yerevan State University
}

$\mathrm{B}$ efore we proceed with our analysis, we would like to dwell on the brief representation of the phenomenon known as supraphrasal reported speech.

Supraphrasal reported speech is the reported speech presented as a supraphrasal unity ${ }^{1}$ which is considered to be a unit of text larger than a sentence, and which is characterized by topical, communicative and structural completeness.

Thus, the study of supraphrasal reported speech takes us beyond the boundaries of an isolated, single sentence, enabling us to present a more comprehensive picture of reported speech.

Reported speech on the supraphrasal level is called Reported Speech Complex $R S C^{2}$. RSC may contain two or more sentences. However, sometimes RSC can be presented as a complex sentence which consists of several clauses.

This is conditioned by the fact that when transposing direct speech into an indirect one, several independent sentences are changed into a complex sentence with several clauses. This phenomenon can be explained by the tendency of language towards economy.

The main structural types of supraphrasal reported speech that we differentiate are monologic supraphrasal reported speech ${ }^{3}$ and dialogic supraphrasal reported speech.

In the present article we are mainly concerned with the analysis of the means which connect the components of monologic supraphrasal reported speech and provide its semantic, communicative and structural completeness. These means of connection are neatly divided into explicit and implicit ones. Let us introduce and discuss these two types separately.

\section{Explicit Means Used in Monologic Supraphrasal Reported Speech}

Explicit means which are used to link the components of monologicsupraphrasal reported speech are: 1) anaphoric and cataphoric substitution; 2) conjunctions (coordinating and subordinating); 3) syntactic parallelism; 4) epanalepsis.

1) Anaphoric and cataphoric relations existing between linguistic units play a great role in the process of decoding the content of the text. Let us define the type of these anaphoric and cataphoric relations. Anaphora expresses retrospective relations, that is, it refers back to preceding information, while cataphora expresses prospective relations, thus, it refers to succeeding information. Both of these relations occur on the level of supraphrasal reported speech. It should be mentioned that anaphora is present in almost all forms and types of supraphrasal reported speech. 


\section{Anaphora}

They sat around the table and Annabelle told them about the library of books that had become a termite's nest and they all listened. She said she had searched for George Bigges' photographic plates but had not found them. These, she said, would have been great prize.

(Miller:222)

In the given example we have the following substitutions: Annabelle - she; photographic plates - these.

\section{Cataphora}

The baker told the story of his daughter and Enzo. A fine Italian lad from Sicily; captured by the American Army; sent to the United States as a prisoner of war; given parole to help our war effort! A pure and honorable love had sprung up between honest Enzo and his sheltered Katherine but now that the war was ended the poor lad would be repatriated to Italy and Nazorine's daughter would surely die of a broken heart. Only Godfather Corleone could help this afflicted couple. He was their last hope. (Puzo:7)

In the above mentioned example the expression "the story of his daughter and Enzo" refers to the succeeding information. To decode its meaning, one should pay attention to the sequence of sentences following the first one.

2) Conjunctions which are of two types - coordinating and subordinating, are used to connect preceding reported speech to succeeding in order to form a unified reported speech complex. The number of reported sentences oscillates from 2 to 5 .

Coordinating (and, but, also, still, so, besides, for, etc.) and subordinating (that, how, as, if, whether, etc.) conjunctions may occur both on separate sentence level and within the boundaries of a sentence. In RSC conjunctions are used to connect more than one RSS (if there are) and more than one Rs within RSS.

\section{Coordinating conjunctions}

$>R c+2 R s$ (RSS)

1) Anxious to display my erudition in the culinary arts, I remarked that the meat was not good enough for patties, and, besides, that there was not enough of it.

(Gorky:11)

\section{$2 \mathrm{Rc}+3 \mathrm{Rs} \quad(2 \mathrm{RSS})$}

2) He says there is a great improvement in them and he thinks the danger of her losing her sight completely is past. But he says she'll never be able to read much or do any fine hand-work again.

(Montgomery:63)

3) Chester Sloane says we'll do nothing all the time in heaven but walk around in white dresses and play on harps; and he says he 
hopes he won't have to go till he's an old man, because maybe he'll like it better then. And he thinks it will be horrid to wear dresses and I think so too.

(Montgomery:66)

\section{Subordinating conjunctions}

$>R c+2 R s$

1) There were those who said that he was dead, that the Vorst who occasionally appeared at the chapels of the Brother-hood was a robot, a simulacrum.

(Silverberg:116)

$R c+5 R s$

2) Afterwards, while we were having our tea, he talked on -disconnectedly, in words one does not hear in ordinary conversation: of how she had been a country gentlewoman, and he a history teacher; how he had been engaged to tutor her son, and had fallen in love with her; how, for him, she had left her husband - a German, and a baron; how she had sung in Opera, and how happy they had been together, though the baron did everything in his power to poison life for her.

(Gorky:70)

Our analysis has revealed that particles can also play the role of a conjunction between the components of supraphrasal reported speech:

1. And then Don Tommasino had told Michael that the two shepherds, Fabrizzio and Calo, would go with him as bodyguards in the Alfa Romeo. Don Tommasino would say his good-byes tonight since he would be off early in the morning, at dawn, to see to his affairs in Palermo. Also, Michael was not to tell Dr. Taza about the move, since the doctor planned to spend the evening in Palermo and might blab.

(Puzo:165)

2. He told us we ought to think of Jesus as our buddy and all. He said he talked to Jesus all the time. Even when he was driving his car.

(Salinger:10)

3. After we sat down to our waffles and sausage, Jake told us how pleased the Shimerdas had been with their presents; even Ambrosch was friendly and went to the creek with him to cut the Christmas tree.

(Cather:96)

4. Because Father said clocks slay time. He said time is dead as long as it is being clicked off by little wheels; only when the clock stops does time come to life.

(Faulkner:128) 
The examples illustrating the use of subordinating and coordinating conjunctions in monologic supraphrasal reported speech come to prove that the connection between Rs through conjunctions are found both on the separate sentence level and on the clause level.

3) The main essence of syntactic parallelism is in the repetition of one and the same syntactic pattern in the chain of sentences. In case of supraphrasal reported speech syntactic parallelism is realized through the repetition of the parts of Reported speech structure (RSS) which consists of reporting context (Rc) and reported speech (Rs), and in this structure mainly the part of reporting context is repeated. Rc can be expressed by one and the same verb, or can combine the lexical synonyms of reporting verbs: say, tell, add, express, announce, declare, assert, confirm, etc. The number of syntactic repetitions which provide the continous flow of speech differs from author to author. Here are some examples:

\section{RSS}

1) He said it was too late to start if I'd never done it before. He said I could ski if I wouldn't fall down.

(Hemingway:125)

\section{$3 \mathrm{RSS}$}

2) He told us we should always pray to God - talk to Him and all - wherever we were. He told us we ought to think of Jesus as our buddy and all. He said he talked to Jesus all the time. (Salinger:10)

3) They asked first that he renounce the revision of property titles in order to get back the support of the Liberal landowners. They asked, secondly, that he renounce the fight against clerical influence in order to obtain the support of the Catholic masses. They asked, finally, that he renounce the aim of equal rights for natural and illegitimate children in order to preserve the integrity of the home.

(Marquez:87)

\section{RSS}

4) She says everybody has been so kind to her since she came here as a bride that she feels as if she were leaving lifelong friends. And then, there's the baby's grave, you know. She says she doesn't see how she can go away and leave that . . it was such a little mite of a thing and only three months old, and she says she is afraid it will miss its mother, although she knows better and wouldn't say so to Mr. Allan for anything. She says she has slipped through the birch grove back of the manse nearly every night to the graveyard and sung a little lullaby to it.

(Montgomery:132)

\section{$5 \mathrm{RSS}$}

5) $\boldsymbol{A}$ British major at the club told me the Italians had lost one hundred and fifty thousand men on the Bainsizza plateau and on 
San Gabriele. He said they had lost forty thousand on the Carso besides. We had a drink and he talked. He said the fighting was over for the year down here and that the Italians had bitten off more than they could chew. He said the offensive in Flanders was going to the bad. If they killed men as they did this fall the Allies would be cooked in another year. He said we were all cooked but we were all right as long as we did not know it. We were all cooked.

(Hemingway:57)

Our study of examples leads us to the idea that the number of RSS in a RSC varies from 2 to 5 . It should be mentioned that we have not come across instances of monologic supraphrasal reported speech where there are more than five RSS in a RSC. It is said that this kind of structure is conditioned by certain psychological factors (i.e. by the ability of the human being to store and save in his/her memory what he or she has heard, and later report it as a sequence of sentences which will form a logical and comprehensible speech (Miller:1956)).

It should be stated that repetition can occur not only in Rc, where mainly the reported verb is repeated, but also in Rs, or even the conjunction can be repeated. For example:

1. She once told Sally I was wild. She said I was wild and that I had no direction in life.

(Salinger:33)

2. Paul could have said that since he was alone, he had no need for a house this big anymore. Or that the home was more suited to someone younger, who didn't mind the stairs. Or that he was planning to buy or build a different home and wanted a different decor. Or that he planned to retire, and all this was too much to take care of.

(Sparks:25)

As it is seen, in our first example a whole clause (I was wild) is repeated; in the second example the combination of coordinating and subordinating conjunctions (or that) is repeated.

It is striking to observe instances of ellipsis occurring in monologic supraphrasal reported speech when in case of syntactic repetition the reproducer or, the so-called Second speaker ( $\mathrm{S}_{2}-$ the grammatical subject of the sentence) is deleted in the succeeding Rc (whether they are two, three or four). Ellipsis is either the result of the tendency of language towards economy, or the result of stressing the more important communicative part of the speech:

1. He says he believes you are some good after all, even if you are a girl. Says that whipping you gave him was just as good as a man's.

(Montgomery:57) 
2. Then Cohn said he wouldn't hit him again. Said he couldn't do it. Said it would be wicked.

(Hemingway:106)

4) Another more striking point which attracted our attention when examining samples of monologic supraphrasal reported speech is the use of the type of repetition which is called epanalepsis. Epanalepsis is a figure of speech which is characterized by the repetition of the same word, clause or sentence at the beginning and at the end of the given syntactic unit strongly emphasizing it. We have come across monologic supraphrasal reported speech complexes which begin and end by Rc (reporting context). This kind of beginnings and endings, figuratively speaking, are a kind of gates which open and close the realm of supraphrasal reported speech. They mark the boundaries of reported speech very vividly, i.e. make it easy to define its limits when necessary and emphasize its semantic wholeness:

1. They said they could not drink the tea; that it was hogwash. Their fathers were magistrates, the fellows said. (Joyce:6)

2. She said the way to save the Ranna Valley from being dammed would be if we found a site of national importance down here. Something to get the attention of the Council on Monuments and Sites, she said. (Miller:175)

3. He said it had been a very pleasant race, and would have been worth watching if Bottechia had not abandoned it at Pamplona. The dust had been bad, but in Spain the roads were better than in France. Bicycle roadracing was the only sport in the world, he said. (Hemingway:123)

\section{The Expression of Implicit Connection in Monologic Supraphrasal Reported Speech}

The semantic interconnection between elements, units of supraphrasal reported speech is realized not only explicitly, i.e. with the help of conjunctions, substitution, syntactic parallelism, etc., but also implicitly, i.e. without direct and explicit means of connection.

Implicit connection is conditioned by logical-semantic relations existing between the components of supraphrasal reported speech. Such kind of relations are as follows: 1) causative-consequential relations, 2) appositive relations, 3) temporal relations.

\section{Causative - consequential relations \\ $>R c+2 R s$ \\ 1) The nurse came in and told them they would have to leave. The resident was going to do some work on Lucy and needed privacy.}




\section{$\mathrm{Rc}+3 \mathrm{Rs}$}

2) She says she'll have to go and live with Eliza and it's breaking her heart to think of leaving Avonlea. A woman of her age doesn't make new friends and interests easy.

(Montgomery:129)

3) He says he can't take the children this spring... he's been sick most of the winter and his wedding is put off.

(Montgomery:64)

The above mentioned examples clearly reflect the fact that causative relations exist between separate sentences which, in case of transformation, can be expressed more vividly by adding the subordinating conjunction "because" in the right place.

\section{Appositive relations}

$R c+3 R s$

1) James said the roof and floor had all fallen in, and that only the black walls were standing; the two poor horses that could not be got out were buried under the burnt rafters and tiles.

(Sewell:75)

2) Langdon quickly told her about works by Da Vinci, Botticelli, Poussin, Bernini, Mozart, and Victor Hugo that all whispered of the quest to restore the banished sacred feminine. Enduring legends like Sir Gawain and the Green Knight, King Arthur, and Sleeping Beauty were Grail allegories. Victor Hugo's Hunchback of Notre Dame and Mozart's Magic Flute were filled with Masonic symbolism and Grail secrets.

(Brown:135)

\section{$R c+4 R s$}

3) She told the don to spare her husband's life and forgive the debt. In return, she would give him a son. But not the one she had with her husband, not Giani. She would give Don Nikola a son of their own, one who would have Rosiblood rushing through his veins. (Carcaterra:344)

In the given examples the connection between the components of supraphrasal reported speech is conditioned by appositive relations. In these examples the succeeding sentence reveals or uncovers the meaning of the preceding one.

\section{Temporal relations}

\section{$\mathrm{Rc}+4 \mathrm{Rs}$}

1) In Kazan, Yevreinov said, I would stay with him, studying through the autumn and winter to master the gymnasia program. Then I would take "some few" examinations - that was just how he put it: "some few"; the University would grant me a scholarship; and in five years or so I would be a "learned man".

(Gorky:8) 


\section{$\mathrm{Rc}+6 \mathrm{Rs}$}

2) All through the wheat season, she told us, Ambrosch hired his sister out like a man, and she went from farm to farm, binding sheaves or working with the threshers. The farmers liked her and were kind to her; said they would rather have her for a hand than Ambrosch. When fall came she was to husk corn for the neighbours until Christmas, as she had done the year before; but grandmother saved her from this by getting her a place to work with our neighbours, the Harlings.

(Cather:58)

In the examples adduced above, the inner logical connections between the elements of RSC are based on the chronological succession of the events.

So, it goes without saying that the abundant illustrative material - examples, are of tremendous help in clarifying and elucidating the use of different types of explicit and implicit means of connection, as well as in presenting the visually comprehensive picture of monologic supraphrasal reported speech. The analysis of the examples makes it clear that in case of explicit connection the number of Rs can amount to five, while in case of implicit connection the number of Rs excels five.

Thus, our brief analysis enables us to make a conclusion that both explicit and implicit means of connection are equally important in providing the structural, semantic and communicative completeness of a monologic reported speech represented as an original and distinctive type of supraphrasal unity.

\section{Notes:}

1. Different linguists name this syntactic unit differently: "complex syntactic unity" (Galperin), "microtext" (Moskalskaya), "supraphrasal unit" (Harutyunova), "supraphrasal unity" (Fridman), "discourse" (Harris), "supra-sentential construction" (Blokh). In the Russian philological tradition also the following terms were used to refer to such formations: "phrase", "strophe", "prosaic strophe", "component", "paragraph", "period", "syntactic complex", "communicative bloc". However, in our study we have used the term proposed by L. Fridman-"supraphrasal unity".

The essence of supraphrasal unity is more or less clearly formulated in I.R. Galperin's definition: "The term supraphrasal unit (SPU) is used to denote a larger unit than a sentence. It generally comprises a number of sentences interdependent structurally (usually by means of pronouns, connectives, tense-forms) and semantically (one definite thought is dealt with). Such a span of utterances is also characterized by the fact that it can be extracted from the context without losing its relative semantic independence. This cannot be said of the sentence, which, while representing a complete syntactical unit, may, however, lack the quality of independence. A sentence from the stylistic point of view does not necessarily express one idea, as it is defined in most manuals of grammar. It may express only part of one idea" (Galperin 1977:194). 
The supraphrasal unity is characterized by almost all the parameters which are typical of the text: cohesion, pronominality, completeness, etc. (Mkhitaryan, Chubaryan 2008:375)

2. Every component of RSC, that is, each complex sentence presents the following structure consisting of two parts:

1) The main sentence or reporting context $(\mathbf{R c})$ representing the second speaker's words

2) Reported speech proper(reported speech - Rs)

Thus, the reported speech structure (RSS) can be graphically presented in the following way:

$$
R S S=R c+R S
$$

It is not difficult to guess that RSC contains two and more RSS and, correspondingly, one RSS may contain more than one Rs. RSC as any other Supraphrasal unity is characterized by semantic and structural coherence of its parts.

3. A clear demarcation line is drawn between monologic speech and dialogic speech. Monologic is considered to be the speech or sequence of sentences which is directed from one speaker to one or more than one listener. This kind of sequence is called "one - direction sequence" by M. Blokh. M. Blokh uses the terms "cumulative sequence" or "cumuleme" to refer to monologic supraphrasal reported speech: "The formation of a one-direction sequence is based on syntactic cumulation of sentences, as different from syntactic composition of sentences making them into one composite sentence. Hence, the supra-sentential construction of one-direction communicative type can be called a cumulative sequence, or a cumuleme." (Blokh 1983:363-365).

\section{References:}

1. Blokh, M.Y. (1983) Teoreticheskaya grammatika angliskogo yazika. M.: Vyshaya Shkola.

2. Pribytok, I.I. (2006) Lektsii po teoreticheskoi grammatike angliskogo yazika. / Uchebnoe posobiye dlya studentov Ш - IV kursov lingvist. spetsial'nostey. Saratov: Nauchnaya kniga.

3. Galperin, I.R. (1977) Stylistics. M.: Higher School.

4. Mkhitaryan, Y.; Chubaryan, A. (2008) Theoretical English Grammar. Yerevan: YSU Press.

\section{Sources of Data:}

1. Brown, D. (2006) The Da Vinci Code. Anchor.

2. Carcaterra, L. (2004) Paradise City. Pocket Books.

3. Cather, W. (2000) My Antonia. New Millennium Library.

4. Faulkner, W. (1995) The Sound and the Fury. Vintag. 
5. Gorky, M. (1953) My University. Moscow: Foreign Language Publishing House.

6. Hemingway, E. (1997) A Farewell to Arms. First Scribner Edition.

7. Hemingway, E. (2006) The Sun Also Rises. Scribner.

8. Joyce, J. (1982) Dubliners \& A Portrait of the Artist as a Young Man. Moscow: Progress Publishers.

9. Marquez, G.G. (2003) One Hundred Years of Solitude. Harper.

10. Miller, A. (2002) Journey to the Stone Country. Hodder and Stoughton.

11. Montgomery, L.M. (1997) Anne of Avonlea. Random House Children's Books.

12. Puzo, M. (2002) The Godfather. New American Library.

13. Salinger, J.D. (2001) The Catcher in the Rye. Little Brown Book Group.

14. Sewell, A. (2003) Black Beauty. Scholastic Inc.

15. Silverberg, R. (1978) To Open the Sky. Berkley.

16. Sparks, N. (2009) Nights in Rodanthe. Little Brown Book Group.

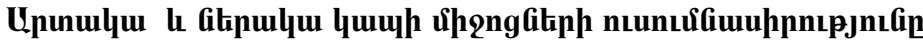

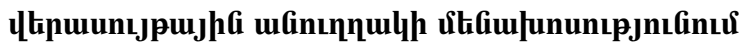

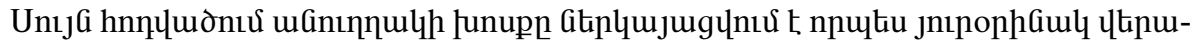

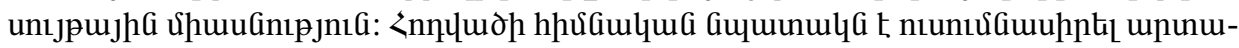

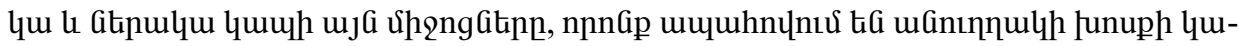

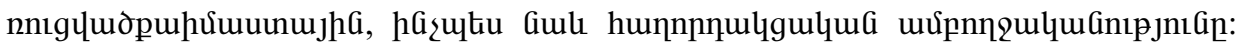

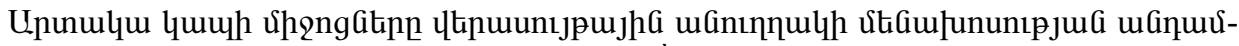

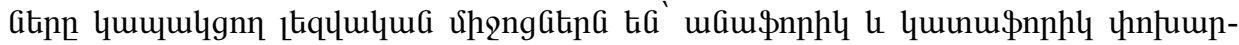

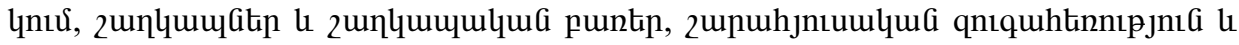

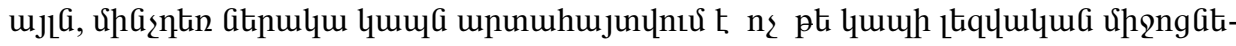

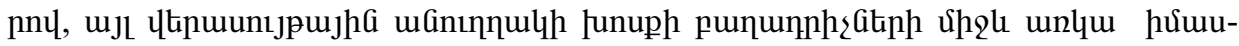

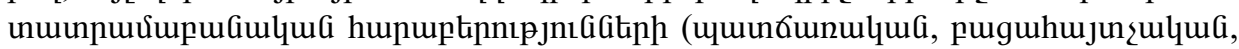

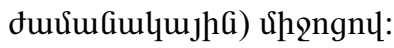

